\title{
Ensino de divisão numa escola rural de Dourados-MS (1989): uma análise do caderno de planejamento
}

\author{
Division teaching in a rural school in Dourados \\ (1989): an analysis of the planning copybook
}

Enseñanza de división en una escuela rural del interior de Dourados (1989): un análisis del cuaderno de planificación

\author{
AlESSANDRA CRISTINA FURTADO ${ }^{D}$ a \\ MARIA DO CARMO BRAZIL (iDb \\ EDVONETE SOUZA DE AlEnCAR (iDc
}

\section{Resumo}

0 presente artigo insere-se nas abordagens sobre a história das instituições escolares rurais no sul de Mato Grosso (atual Mato Grosso do Sul), de modo a analisar e contribuir para a compreensão da seguinte problemática: Como foi tratado o ensino da divisão matemática em uma escola rural de $1^{\underline{0}}$ grau do interior de Mato Grosso do Sul, no final da década de 1980? Assim, este artigo busca analisar o ensino da divisão para crianças da $2^{\underline{a}}$ série do $1^{\text {o }}$ grau na Escola Municipal Padre Anchieta, em Vila Formosa, distrito do município de Dourados, tomando como fonte principal de pesquisa um "Caderno de Planejamento" de uma professora que atuou em 1989. A delimitação do estudo justifica-se em razão de o Caderno da professora ter sido planejado e escrito no ano de 1989. A pesquisa desenvolveuse na perspectiva da Nova História Cultural e com base em fontes documentais. Os dados apontaram que os registros apresentados pela docente no Caderno estavam centrados no ensino dos algoritmos, o que mostrou a influência da Matemática Moderna das décadas de 1960 a 1970. Tal movimento educacional incentivava o ensino de Matemática mais lógico, centrado no ensino das estruturas, dos algoritmos e da linguagem matemática. Além disso,

\footnotetext{
a Universidade Federal da Grande Dourados (UFGD), Dourados, MS, Brasil. Doutora em Educação, email: alessandra_furtad@yahoo.com.br

b Universidade Federal da Grande Dourados (UFGD), Dourados, MS, Brasil. Doutora em História Social, e-mail: mc2708@hotmail.com

c Universidade Federal da Grande Dourados (UFGD), Dourados, MS, Brasil. Doutora em Educação Matemática, e-mail: edvonete.s.alencar@hotmail.com
} 
este estudo permitiu perceber que o ensino da divisão apresentou indícios de uma concepção pedagógica tradicional. Conclui-se, assim, que o ensino da divisão esteve influenciado pela Matemática Moderna e baseado em uma concepção pedagógica tradicional.

Palavras-chave: Caderno Escolar. Ensino da Divisão. Escola Rural.

\begin{abstract}
The present article is part of the approaches to the history of rural school institutions in Southern Mato Grosso (now Mato Grosso do Sul), in order to analyze and contribute to the understanding of the following problem: How was the teaching of the mathematical division in a rural elementary school in the interior of Mato Grosso do Sul in the late 1980s? Thus, this article seeks to analyze the teaching of the division to children of the second grade of elementary school, of the municipal school Padre Anchieta, Vila Formosa, district of the Dourados municipality, taking as main source of research a "Planning Copybook" of a teacher who worked there in 1989. The study's borders are justified because the teacher's notebook was planned and written in the year 1989. The research was developed from the perspective of the New Cultural History and based on documental sources. The data showed that the registers presented by the teacher in the copybook were centered in the teaching of the algorithms, which showed the influence of Modern Mathematics from the 1960s to 1970s. This educational movement encouraged the teaching of more logical Mathematics, centered in the teaching of structures, algorithms and mathematical language. In addition, this study showed that the teaching of the division showed signs of a traditional pedagogical conception. It is concluded, therefore, that the division's teaching was influenced by Modern Mathematics and based on a traditional pedagogical conception.
\end{abstract}

Keywords: School copybook. Division Teaching. Rural School.

\title{
Resumen
}

El presente artículo se inserta en los enfoques sobre la historia de las instituciones escolares rurales en el sur de Mato Grosso (actual Mato Grosso del Sur), para analizar y contribuir a la comprensión de la siguiente problemática: ¿cómo se ha tratado la enseñanza de la división matemática en una escuela rural de primer grado del interior de Mato Grosso del sur, al final de la década de 1980? En este artículo se busca analizar la enseñanza de la división para niños de la $2^{a}$ serie del $1^{\circ}$ grado, de la Escuela Municipal Padre Anchieta, de Vila Formosa, distrito del municipio de Dourados, tomando como fuente principal de investigación un "Cuaderno de Planificación" de una profesora que actuó en 1989. La delimitación del estudio se justifica debido a que el cuaderno de la profesora fue planeado y escrito en el año 1989. La investigación se desarrolló en la perspectiva de la Nueva Historia Cultural y con base en fuentes documentales. Los datos apuntaron que los registros presentados por la docente en el Cuaderno estaban centrados en la enseñanza de los algoritmos, lo que mostró la influencia de la Matemática Moderna de las décadas de 1960 a 1970. Tal movimiento educativo incentivaba la enseñanza de Matemáticas más lógico, centrado en la enseñanza de las estructuras, de los algoritmos y del lenguaje matemático. Además, este estudio permitió percibir que la enseñanza de la división presentó indicios de una concepción pedagógica tradicional. Se concluye, así, que la enseñanza de la división estuvo influenciada por la Matemática Moderna y basada en una concepción pedagógica tradicional. 
Palabras clave: Cuaderno Escolar. Enseñanza de la División. Escuela Rural.

\section{Introdução}

Toda vez que eu viajava pela Estrada de Ouro Fino de longe eu avistava a figura de um menino que corria abrir a porteira e depois vinha me pedindo: - Toque o berrante seu moço que é pra eu ficar ouvindo (O Menino da Porteira - Teddy Vieira e Luís Raimundo)

A canção sertaneja “O Menino da Porteira”, de autoria de Teddy Vieira e Luís Raimundo, foi gravada pela primeira vez pela dupla Luizinho e Limeira no ano de 1955. Foi interpretada, posteriormente, por Tonico e Tinoco (1956), Sérgio Reis (1973), Tião Carreiro e Pardinho (1976), Daniel (2009), entre outros cantores. A criação de Teddy Vieira e Luís Raimundo ainda passou por duas adaptações cinematográficas, a primeira, em 1976, protagonizada por Sérgio Reis, e a segunda, em 2009, pelo cantor Daniel.

Transformou-se numa das composições mais populares da música caipira brasileira por narrar o drama ficcional de um boiadeiro que, ao passar inúmeras vezes pela cidade de Ouro Fino, cidade do interior mineiro, deparava-se comumente com um menino que abria as porteiras para a passagem do gado em troca de algumas moedas. Certo dia, o menino foi vítima fatal de um acidente, provocado pela fúria de um boi que o atacou. A letra relaciona-se ao universo rural, cujo cenário imaginado é constituído pela condução do gado e envolve vaqueiros na lida, currais, peões, mulheres e crianças em condição de vida rural. Além de se transformar em um dos hinos dos sertanejos e de muitos meninos do interior brasileiro em regiões rurais, a letra aponta para o universo de crianças que enfrentam inúmeras dificuldades, sobretudo, concernentes à saúde e ao acesso à educação.

É deste cenário da vida no meio rural que este artigo emerge com a proposta de contribuir com os estudos sobre a história do ensino rural no Brasil, mais precisamente, acerca das escolas rurais, cujas investigações científicas, como tema central, apresentaram-se de forma mais intensa na última década no campo da pesquisa em História da Educação (ÁVILA, 2018). Assim, o presente artigo insere-se nos estudos que envolvem um projeto maior que visa a investigar a história das 
instituições escolares, a história da formação e da profissão docente no meio rural, no sul do então estado do Mato Grosso, entre as décadas de 40 a $90^{1}$ do século XX.

$\mathrm{O}$ artigo incide em analisar o ensino da divisão matemática para crianças na $2^{\mathrm{a}}$ série do $1^{\mathrm{o}}$ grau, na Escola Municipal Padre Anchieta, situada na Vila Formosa, um distrito pertencente ao município de Dourados. Tomamos como fonte principal de pesquisa um "Caderno de Planejamento" de uma professora que atuou em 1989. O referido Caderno foi encontrado durante uma pesquisa documental no arquivo da Escola Municipal Padre Anchieta. Para tanto, buscamos analisar e contribuir para a compreensão da seguinte problemática: Como foi tratado o ensino da divisão matemática em uma escola rural de $1^{\circ}$ grau, do interior de Mato Grosso do Sul, no final da década de 1980?

A delimitação do recorte temporal justifica-se em razão de o Caderno da professora, tomado como fonte principal do estudo, ter sido planejado e escrito no ano de 1989.

Para desenvolver este artigo, além do Caderno de Planejamento da professora da escola rural, foi necessário recorrermos também a fontes documentais. Utilizamos, ainda, as referências ligadas à História, à História da Educação e à História da Educação Matemática.

A pesquisa desenvolveu-se na perspectiva da Nova História Cultural ${ }^{2}$. Convém lembrarmos que a aproximação da Nova História Cultural com a História da Educação possibilitou que os pesquisadores dessa área passassem a se dedicar a outra proposta de estudo, isto é, a uma proposta voltada a um pluralismo epistemológico e temático. Isso permitiu a sofisticação das abordagens e o enriquecimento do tratamento das fontes (GATTI JÚNIOR, 2002; WARDE, 1990). Para Carvalho (1998), essa aproximação fez com que a pesquisa, nesta área, passasse a se centrar em novos domínios, como:

\footnotetext{
1 Neste item do artigo, optamos por denominar Sul do então estado de Mato Grosso, mesmo abrangendo as décadas de 80 e 90 do século XX, porque o estado de Mato Grosso do Sul somente foi criado em 1977, pelo desmembramento da parte norte e sul de Mato Grosso Uno.

${ }^{2}$ A Nova História Cultural é considerada a principal herdeira de renovação do campo historiográfico intitulado "Nova História" e tem se tornado uma perspectiva privilegiada para a produção de novos textos e novas abordagens.
} 
[...] penetrar a caixa preta escolar, apanhando-lhe os dispositivos de organização e o cotidiano de suas práticas; pôr em cena a perspectiva dos agentes educacionais; incorporar categorias de análise - como gênero - , e recortar temas - como profissão docente, formação de professores, currículos e práticas de leitura e escrita -, são alguns dos novos interesses que determinam tal reconfiguração (CARVALHO, 1998, p. 32).

Novos objetos e temas, novas categorias de análise, novas fontes e novos problemas e procedimentos de análise integraram-se à pesquisa em História da Educação, pois a Nova História Cultural propõe-se identificar como "o modo como em diferentes lugares e momentos uma determinada realidade social é construída, pensada, dada a ler" (CHARTIER, 1990, p. 16). Desse modo, favoreceu outros caminhos para seu fazer e escrever, como, por exemplo, privilegiar a investigação de uma história de uma instituição escolar e incorporar livros e cadernos escolares como fontes de pesquisa, entre outros documentos que fizeram parte do cotidiano escolar de uma instituição educativa.

Antes, porém, de analisarmos o ensino da divisão no "Caderno de Planejamento" da professora da Escola Padre Anchieta de Vila Formosa, nós realizamos duas abordagens necessárias: uma primeira que trata da história dessa escola e outra que versa sobre os cadernos enquanto fontes para a pesquisa em História da Educação, focalizando o "Caderno de Planejamento" da referida professora. Em uma terceira parte, apresentamos uma análise do ensino de divisão, tomando como fonte o caderno de uso escolar da docente.

História da instituição escolar em que a professora do caderno lecionava: a Escola Padre Anchieta de Vila Formosa

A compreensão da existência histórica de uma instituição educativa, para Magalhães (2004), não se dá só pela sua integração na comunidade educativa, mas também pela sua contextualização no quadro de evolução de uma comunidade ou região e, ao sistematizar o seu itinerário de vida na sua multidimensionalidade, confere, no seu entendimento, um sentido histórico. De acordo com as observações de Magalhães (2004), é preciso empenhar um olhar atento para as condições efetivas 
em que se dá a constituição histórica de uma escola numa localidade ou região. É em razão disso que, nesta parte do texto, a história da Escola Padre Anchieta será tratada a partir da perspectiva de Magalhães (2004).

O município de Dourados, no interior do estado de Mato Grosso do Sul, é constituído pelo distrito sede e por mais oito distritos e uma reserva indígena situada em seu entorno. Vila Formosa, onde fica a Escola Padre Anchieta, é um dos oitos distritos que formam o município, conforme pode-se observar no mapa (Figura 1).

Figura 1 - Mapa do Município de Dourados

\section{Município de Dourados}

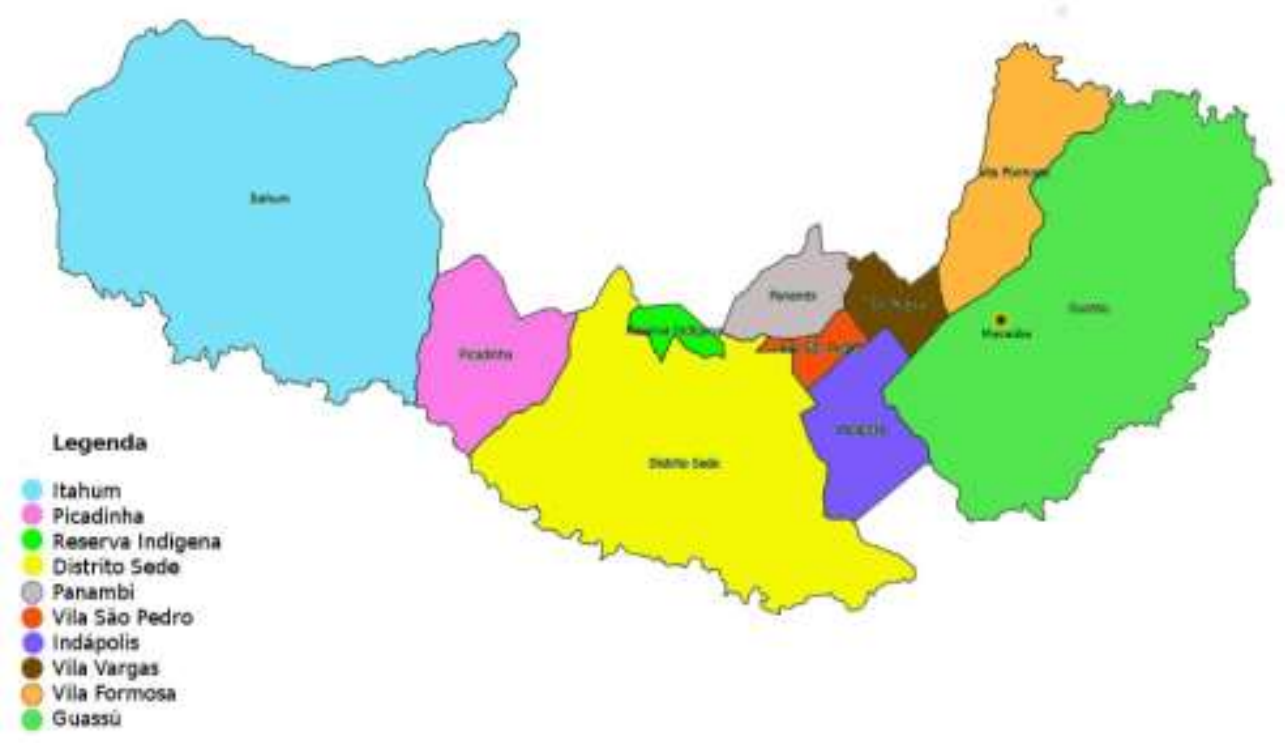

Fonte: Prefeitura Municipal de Dourados-MS.

O distrito de Vila Formosa aparece no mapa assinalado na cor laranja, fazendo limites com os distritos do Guassú e de Vila Vargas; o primeiro está em cor verde e o segundo, em cor marrom. Embora a Vila Formosa não seja um distrito de grandes dimensões territoriais, como é o caso do Guassú e de Itahum, ele se constitui em um distrito de médio porte e que no passado, mesmo não estando situado nas dimensões de abrangência da Colônia Nacional Agrícola de Dourados (CAND), teve as suas 
terras ocupadas por outras frentes de ocupação, atreladas ao movimento de expansão e demarcação territorial.

Antes de adentrar a questão da ocupação territorial nessa região fora das áreas de abrangência da CAND, é oportuno esclarecer que no sul do então estado de Mato Grosso (atual Mato Grosso do Sul), a criação da Colônia Agrícola Nacional foi viabilizada pelo projeto colonizador do presidente Getúlio Vargas por meio de uma intensa propaganda na imprensa, já que havia brasileiros (homens e mulheres) dispostos a enfrentarem os desafios de migrarem para outras regiões do país na tentativa de melhorarem de vida, ou seja, havia uma força de trabalho disponível e, principalmente, barata e desqualificada (OLIVEIRA, 1999).

O presidente Getúlio Vargas utilizou o slogan Marcha para Oeste, com objetivos em seu projeto político de ocupar e povoar os espaços vazios, nacionalizando as fronteiras do sul do Mato Grosso com a Bolívia e, sobretudo, com o Paraguai, promovendo a colonização por meio da presença de trabalhadores rurais. Apesar disso, não se pode esquecer que nesses espaços já havia uma população, sobretudo indígena. No entanto, estes espaços tidos como vazios pelo governo acabaram nesta localidade do sul de Mato Grosso, conquistando novos moradores pela divulgação da boa qualidade das suas terras, a qual poderia favorecer um notável desenvolvimento na região. O governo tentava imprimir uma imagem de futuro, pois, "[...] finalmente integrada ao corpo da nação, a região de fronteira alcançava progresso e desenvolvimento que parte do país desfrutava" (GUILLEN, 1996, p. 43).

O projeto de colonização idealizado por Getúlio Vargas estabelecia-se e dentre suas políticas estava a criação de colônias. No caso do sul de Mato Grosso, foi criada a Colônia Agrícola Nacional de Dourados (CAND), em 1943, pelo Decreto-Lei $n^{\circ}$ 5.941, de 28 de outubro. Porém, a real implantação dessa Colônia somente ocorreu em 20 de julho de 1948, quando da demarcação pelo governo federal, por meio do Decreto-Lei $n^{\circ} 87$, dos seus limites, com a reserva de uma área não inferior a 300 mil hectares (PONCIANO, 2006). Para ocupar as terras da Colônia Agrícola Nacional de Dourados, vieram migrantes de quase todas as regiões, principalmente do Nordeste, além de imigrantes de países da América Latina, da Europa e da Ásia, como o Japão.

No caso da região onde está situada a Vila Formosa, um novo cenário de povoamento ocorreu, conforme registra Naglis (2007). Nesse novo cenário, podemos 
dizer que a região de Vila Formosa, do mesmo modo que a do Guassú, passou por uma frente de ocupação no processo de povoamento com a compra e a venda de títulos de terras consideradas devolutas ${ }^{3}$. Desse modo, o povoamento foi se originando da busca por terras devolutas e também foram sendo adquiridas terras por pessoas antes ligadas à atividade de extração da erva-mate e outros. Observamos, ainda, que os loteamentos rurais impulsionaram um fluxo de pessoas à espera de um pedaço de terra. Foi nesse contexto que surgiram as vilas e os travessões, que passaram também a compor o município de Dourados, com um aglomerado de famílias. Foi assim, ao que tudo indica, que surgiu o vilarejo denominado de Vila Formosa, por onde circularam pessoas com interesse em terras, tanto para compra quanto para venda.

Uma retomada dos dizeres de Magalhães (2004), acerca da compreensão da existência histórica da instituição educativa, permite considerarmos que foi nesse cenário rural, marcado por um processo de colonização recente, que a Escola Municipal Padre Anchieta foi instalada no início da década de 1960, mais precisamente no ano de 1965, na comunidade de Vila Formosa, até então pertencente ao distrito do Guassú, município da Comarca de Dourados, MT. A criação efetivou-se a partir das iniciativas dos pais de crianças em idade escolar, bem como dos demais moradores da localidade, interessados na instalação de uma escola primária. De acordo com Bicudo $(2017)^{4}$, o movimento de criação dessa escola na Vila Formosa teve como único objetivo atender às crianças dessa comunidade, uma vez que, ainda na década de 1960, nessa Vila e em seu entorno, havia um grande número de analfabetos. Além disso, as escolas mais próximas ficavam no distrito de Vila Vargas e no distrito de Douradina, hoje um município de Mato Grosso do Sul.

Ainda na década de 1960, a escolarização não tinha atingido os extremos do sul do estado de Mato Grosso. O atendimento por escolarização não atingia a toda a demanda. Assim, havia um espaço aberto no sistema educacional em Mato Grosso. As mensagens de governadores registraram que o estado tinha dificuldades em

\footnotetext{
${ }^{3}$ Neste caso, as terras devolutas eram aquelas que pertenciam à União e que naquele momento tinham deixado de ser arrendadas pelo governo para a Companhia Mate Laranjeira, para a produção e extração da erva-mate.

${ }^{4}$ Esses dados foram retirados do trabalho de graduação em Pedagogia e do trabalho de iniciação científica de Camila Paula Bicudo (bolsista nos anos de 2016 e 2017 - CNPq). 
organizar e manter o ensino em seu território. A esse respeito, a mensagem de governador do ano de 1962 aponta:

\begin{abstract}
No ensino primário, é muito sensível a nossa falta de classes, apesar das anomalias verificadas, de existirem 1.350 professores orçamentados na lei estadual de meios para este exercício, enquanto, por outro lado, existem 1.853 percebendo pela rubrica respectiva, o que força, sem dúvida a suplementação de verba, além, de contrariar a Lei respectiva. Mas, ainda assim, precisamos dotar para 1.200 professores, a fim de atender de maneira mais eficiente, as reais necessidades, eis que, só em Dourados, nada menos de 50 classes, antes custeado pelo CAND foram transferidas à responsabilidade do Estado, em virtude do convênio assinado no final da passada gestão com o INIC (MATO GROSSO, 1962).
\end{abstract}

Um dos percalços nessa realidade era a falta de escolas suficientes para atender a todas as crianças em idade escolar das áreas rurais. As dificuldades de funcionamento das escolas perpassavam principalmente a falta de docentes com habilitação, o que dificultava o processo de escolarização.

Assim, a escola em Vila Formosa, que depois foi transformada em Escola Padre Anchieta, foi instalada nesse cenário marcado por grandes índices de analfabetismo e pela falta de escolas suficientes para atender a toda a demanda de crianças em idade escolar que residiam na localidade. Entretanto, suas origens vêm da transferência da instituição da Vila Sapé — distrito de Douradina, para a Vila Formosa — do distrito do Guassú. Nesse período, a professora Laurita Saraiva Sampaio, que atuava na Escola Rural Mista do Mercado de Vila Sapé desde o ano de 1961, foi cedida pela Prefeitura Municipal de Dourados para atuar como professora e responsável pela escola de Vila Formosa.

A escola de Vila Formosa foi instalada, inicialmente, na própria casa da professora Laurita, contando com 65 alunos das mais variadas idades. As aulas eram ministradas no período matutino em uma sala de aula multisseriada. Entretanto, em 1966, os pais dos alunos reuniram-se e construíram o primeiro prédio da escola. Assim, a escola deixou de funcionar na casa da professora Laurita e estabeleceu-se em seu novo endereço na Rua Castro Alves, s/n, em Vila Formosa (BICUDO, 2017).

Mesmo com a construção do primeiro prédio da escola, a sua estrutura ainda era muito simples por possuir apenas uma sala grande e uma cozinha, totalmente feitas de barro e sapé. Os alunos não tinham mesas nem mesmo cadeiras; na sala, havia apenas alguns bancos feitos de madeira, os quais os alunos faziam como mesa para escrever as lições, e todos sentavam-se no chão. Também havia na sala um pequeno quadro usado pela professora Laurita para passar as lições diárias aos alunos. 
Contudo, em meados de 1966, o prefeito Napoleão Francisco de Souza, em visita à escola, surpreendeu-se com o seu estado precário de funcionamento. Depois dessa visita, o prefeito fez a doação de mobiliários à escola.

Em 1967, com o crescimento da escola, a instituição de ensino foi elevada a escola reunida 5 , passando a ser chamada de Escola Reunida de Vila Formosa. Nesse mesmo ano, além da mudança na nomenclatura, foi mudado o seu local de funcionamento, pois a escola foi construída em um novo prédio, em um terreno de um hectare $(100 \times 100 \mathrm{~m})$ localizado à margem da Rodovia MT 470. A sede da nova escola foi construída com três blocos, sendo 2 de alvenaria e 1 de madeira. A Figura 2 permite-nos entrever como era essa construção:

Figura 2 - Escola Reunida de Vila Formosa (1969)

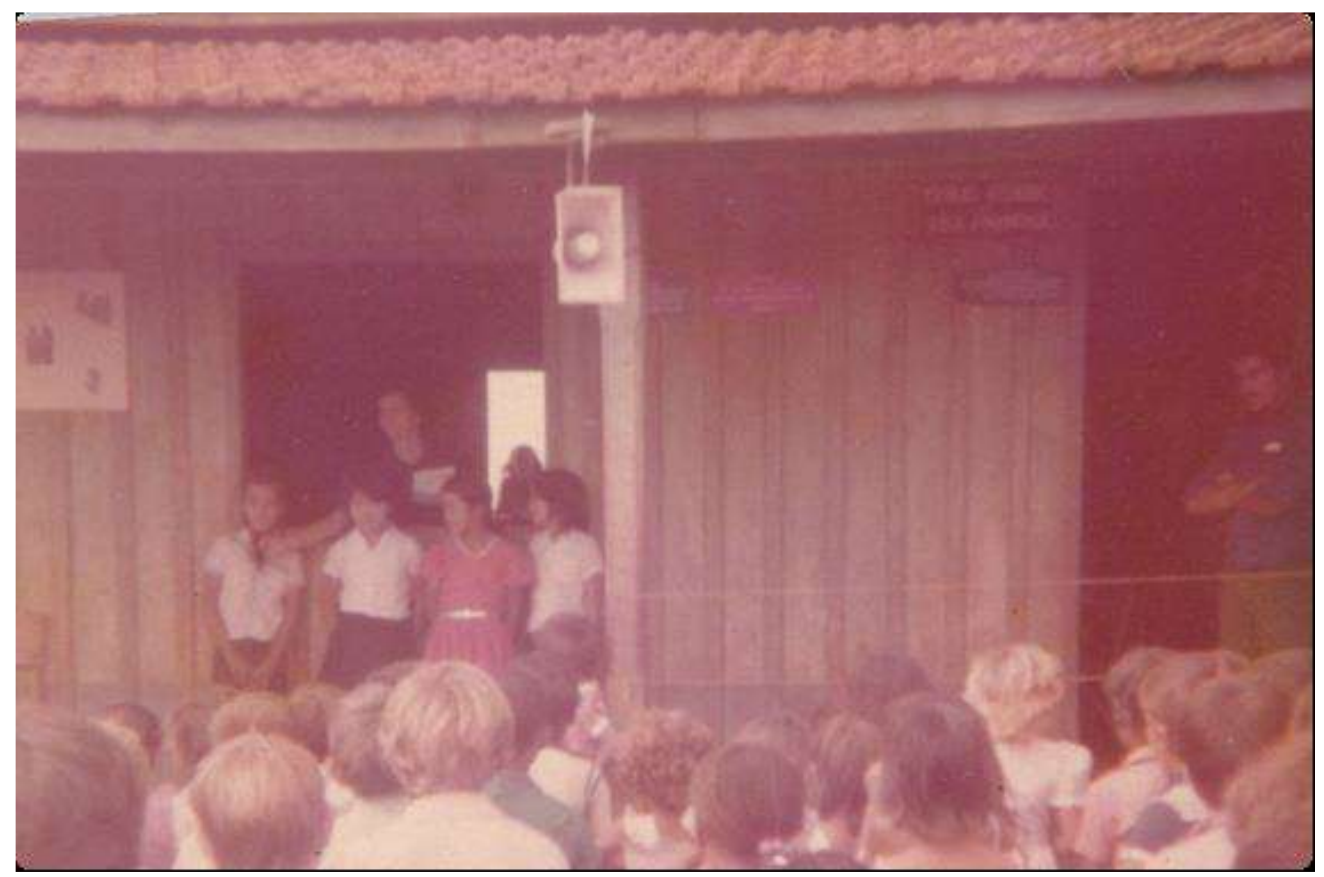

Fonte: BICUDO (2017).

A imagem do ano de 1969 representa uma comemoração na escola e nos permite vislumbrar parte do novo prédio construído em 1967. Além disso, neste caso

\footnotetext{
${ }^{5}$ As escolas reunidas eram uma modalidade escolar, implantada em alguns estados brasileiros, que tinha sua organização espacial e curricular baseada nas normativas que regiam os grupos escolares. Essas escolas não ostentavam construções de prédios grandiosos, mas atendiam diferentes classes, sendo instaladas nas diferentes localidades.
} 
específico, oportuna visualizar o bloco construído em madeira e todo coberto por telhas de cerâmica. Ainda que a nova construção tenha possibilitado a vinda de novos mobiliários para a escola, como mesas, carteiras e um quadro negro, as salas de aulas não eram separadas, pois havia apenas um grande salão, o qual era dividido pelas professoras.

Entretanto, foi somente em 23 de setembro de 1974 que o Sr. João da Câmara, então prefeito de Dourados, formalizou, por meio do Decreto n $296 / 74$, a criação oficial da Escola Municipal Padre Anchieta ${ }^{6}$. O Curso Ginasial somente foi oferecido quatro anos depois da criação oficial, basicamente no final da década de 1970. Desse modo, a escola passou a oferecer o ensino de $1^{\circ}$ grau completo conforme prescrevia a Lei $n^{\mathrm{o}} 5.692 / 71$, atendendo alunos de $1^{\mathrm{a}}$ a $4^{\mathrm{a}}$ séries e de $5^{\mathrm{a}}$ a $8^{\mathrm{a}}$ séries do $1^{\mathrm{o}}$ grau.

Em 1986, como o intuito de ampliar o seu funcionamento para além do atendimento de crianças e jovens, a escola passou a oferecer também o Curso de Educação de Jovens e Adultos, no período noturno.

\section{Os cadernos como fontes de pesquisa para a História da Educação: em foco o Caderno de Planejamento da Professora da Escola Padre Anchieta}

Os cadernos começaram a preencher uma enorme fração do tempo e das atividades escolares na metade do século XIX (HÉBRARD, 2001). Segundo Hébrard (2001, p. 121), o caderno "é o testemunho precioso do que pode ter sido e ainda é o trabalho escolar de escrita". Isso nos possibilita afirmar que os cadernos constituem parte importante e fundamental da cultura escolar. Com a mesma linha de reflexão, Mignot (2008, p. 13) aponta o caderno como "objeto quase invisível que guarda a memória da educação" que, a partir das indagações do pesquisador, é capaz de "falar" sobre alunos, professores, pais, projetos pedagógicos, avaliações, valores disseminados e todas as relações e práticas que circundam a escola.

\footnotetext{
${ }^{6} \mathrm{O}$ nome da escola se deu em homenagem ao padre indigenista considerado o primeiro professor do Brasil, Padre Anchieta.
} 
Em Templos de Civilização, livro publicado por Rosa Fátima de Souza (1998), observamos que, no final do século XIX, os materiais escolares ganharam importância no campo da educação e do trabalho docente por facilitarem o processo de ensino-aprendizagem. A partir de observações e "noções empíricas", os materiais escolares passaram a ser entendidos como condição sine qua non para os avanços idealizados naquele momento histórico. Na virada do século XIX para o XX, com destaque para o ano 1890, com o advento do regime republicano no Brasil, princípios básicos do Estado (moralização, civilização e consolidação da ordem social) passaram a nortear as funções básicas da escola.

Impôs-se, assim, uma nova organização do ensino, desencadeada pelo estado de São Paulo com objetivo de racionalizar custos educacionais e estabelecer controle e escolarização da população brasileira. O controle e a disciplina passaram a permear simbolicamente a cultura escolar, envolvendo arquitetura do edifício, disciplina, sistematização dos espaços, bens móveis (carteiras, lousas), controle do tempo, normas de condutas e valores (disciplina, ordem, limpeza, asseio, higiene) (SOUZA, 1998, p. 143).

Souza (1998) explica que o material escolar fazia-se necessário tanto para o ensino da linguagem (cartas de alfabeto, cadernos de caligrafia, coleção de abecedários) como para o ensino de ciências (laboratórios, museus, quadros de história natural). Já para o ensino de geografia e história, por exemplo, eram necessários materiais como globo terrestre, quadros de história do Brasil e mapas.

Desde o início do século XX, a definição de métodos e de materiais no cotidiano escolar foi imprescindível. Para tanto, nas palavras de Souza (1998, p. 168), era indispensável o material, sobretudo, no caso do ensino de aritmética, do sistema métrico decimal e da geometria, os quais se valiam das "cartas de Parker, compassos, contadores mecânicos, quadro de geometria, tabuinhas, contador de mão e de pé, caixa de formas geométricas, cadernos de aritmética".

Para Viñao Frago (2008), os cadernos escolares são fontes de pesquisa para a investigação do ensino, da aprendizagem e da propagação da cultura escrita. O autor considera que estes materiais/documentos estão aptos a oferecerem informações sobre a realidade escolar e as atividades efetuadas na escola. Dessa maneira, podemos 
afirmar que os cadernos escolares acabam se constituindo em uma fonte inesgotável para o estudo. Ademais, mesmo sendo pesquisados por centenas de pessoas, sempre serão observados de forma diferente. Como bem afirma Viñao Frago (2008, p. 15):

Não existe um objeto que contemplado de diversos lugares, seja sempre o mesmo. Da mesma forma, não existe um fenômeno, acontecimento ou assunto que, considerado de perspectivas diferentes não mostre aspectos antes não visíveis ou visíveis, mas não apreciados. Tudo depende, pois, da posição que adota aquele que olha.

Os cadernos, enquanto fontes privilegiadas para a pesquisa, constituem-se, por meio dos conteúdos a que se tem acesso, como uma pista, ou seja, são indícios do ocorrido em sala de aula, conforme apontam Santos (2002, 2008a, 2008b), Faria (1988), Oliveira (2008) e Viñao Frago (2008). Como pistas, de acordo com Viñao Frago (2008), não há como julgarmos o contexto que envolvia as anotações no caderno, pois este era um espaço designado ao registro da produção escrita, de forma que o documento não apresenta o tempo destinado à produção para cada atividade, tampouco as intervenções orais e o vivido em sala de aula. No entendimento deste autor, “o máximo que podemos fazer é nos aproximarmos do passado e reconstruí-lo de modo parcial e com um enfoque determinado" (VIÑAO FRAGO, 2008, p. 25). Nessa mesma perspectiva, Gvirtz e Larrondo (2008, p. 39) esclarecem que é possível compreender o caderno como produto da cultura escolar, por este pertencer a uma instituição específica, na qual atua como dispositivo, transformando saberes, valores ou ideologias em "outra coisa”.

Um aspecto importante a ser esclarecido sobre o "Caderno de Planejamento"7 aqui analisado refere-se ao fato de ele ter sido encontrado no arquivo da escola de Vila Formosa. Esse fato chama a atenção, pois, como aponta Vidal (2000, p. 38), “[...] cadernos de alunos, planos de aula, diários de classe são os primeiros documentos a serem jogados fora do arquivo morto na hora de uma limpeza”. A esse respeito, Mignot (2004, p. 83) lembra que, de modo diferente dos livros,

[...] os cadernos escolares têm sido vistos como menores, insignificantes e desprezíveis, e não são guardados em locais nobres como as bibliotecas. Destinados ao lixo depois de seu uso, são difíceis de serem localizados e não têm merecido a mesma atenção dada a outros impressos, registrados em qualquer suporte físico resultante de processo de produção destinada à venda ou à distribuição gratuita, como monografias, periódicos, publicações em fascículos, fitas K7, Lps, fitas de vídeo, filmes, cds contendo som e/ou imagem, folhetos,

\footnotetext{
${ }^{7}$ Consideramos como "Caderno de Planejamento" os registros de aulas planejadas ou diários de reflexões que permitem ao professor executar suas ações pedagógicas em sala de aula. Salientamos que é uma prática comum dos professores a construção desse tipo de caderno.
} 
livretos e partituras musicais, fotos, estampas, desenhos, medalhas, mapas, plantas, cartazes, sob a guarda daBiblioteca Nacional.

Quanto às características do referido "Caderno de Planejamento", destacamos que se trata de um caderno do tipo brochura. O objeto está bem conservado: a capa e as 96 folhas não estão amassadas ou rasgadas. A primeira dessas folhas está em branco, mas todas as demais páginas estão escritas à caneta, com letra bem legível e, ainda, com registros nas cores azul e vermelho. A capa é dura e de cor preta, conforme se pode observar na Figura 3.

Figura 3 - Capa do Caderno da Professora da Escola Municipal da Vila Formosa, de Dourados, MS, 1989

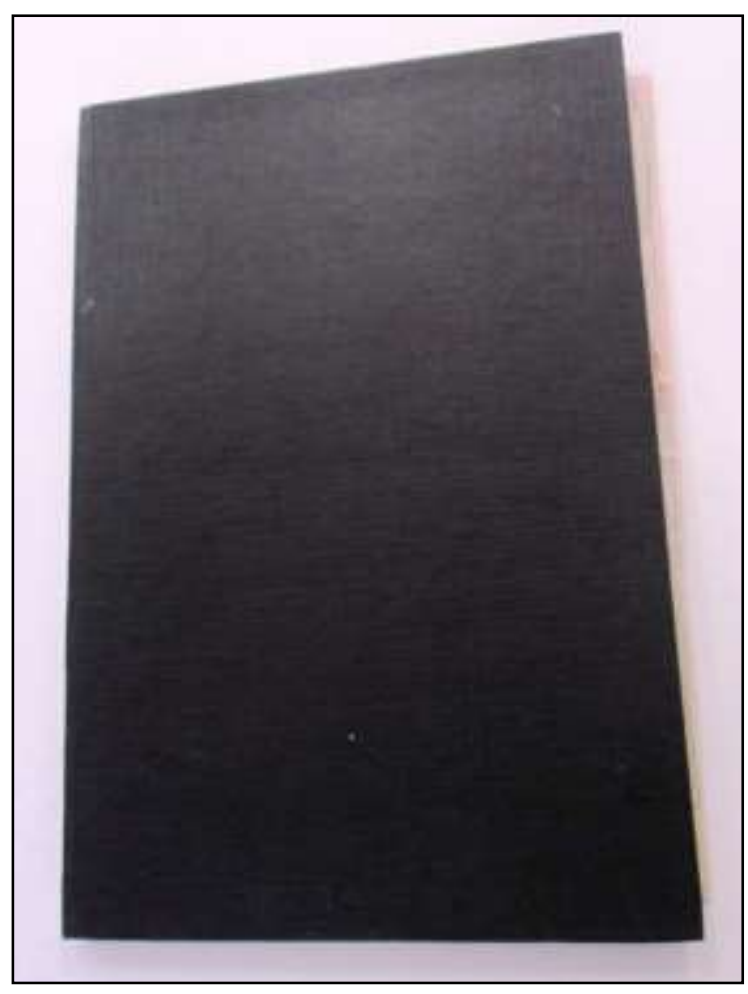

Fonte: Arquivo da Escola Municipal Padre Anchieta, município de Dourados.

Após a primeira folha em branco, o caderno apresenta características que revelam muita ordem e capricho por parte da professora no registro e na organização dos diferentes conteúdos das aulas das disciplinas da $2^{\mathrm{a}}$ série do $1^{\text {o }}$ grau, como podemos notar na Figura 4. 
Figura 4 - Primeira página do Caderno

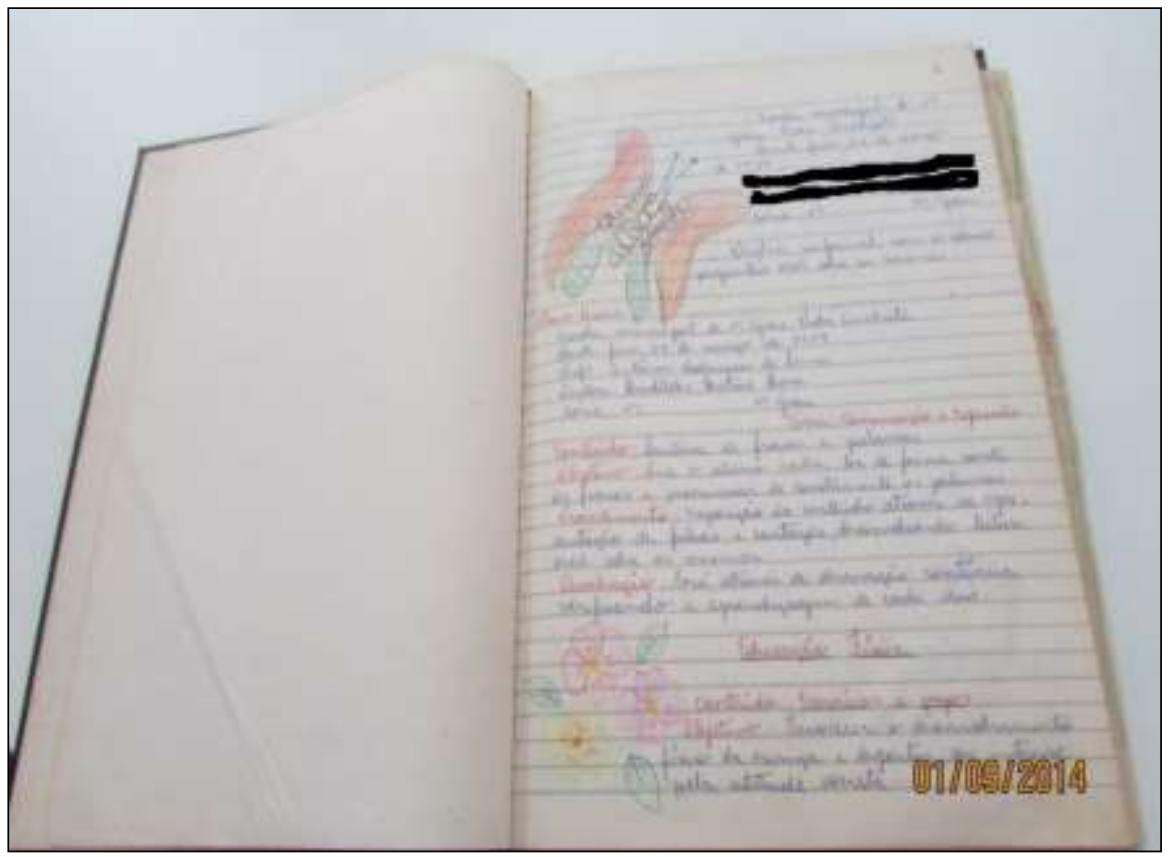

Fonte: Arquivo da Escola Municipal Padre Anchieta, município de Dourados.

Podemos perceber, na Figura 4, que a professora tinha uma forte preocupação com a organização estética de seu caderno de plano diário, pois a maioria das folhas aparece com os conteúdos das diferentes disciplinas registradas ao lado de ilustrações com desenhos feitos à mão e todos coloridos com lápis de cor. São desenhos de flores, animais, frutas, entre outros. No entendimento de Viñao Frago (2008, p. 23), “o 'efeito estético' tem também um sentido ético, regularizador e disciplinar”. Com todo esse "efeito estético", podemos afirmar que a professora procurou organizar as suas aulas, no ano de 1989 , para a $2^{\mathrm{a}}$ série do $1^{\mathrm{o}}$ grau, tendo como ponto de partida os conteúdos das disciplinas registrados no caderno.

Uma rápida análise do caderno nos mostra imediatamente que ele contém anotações de aulas que abordam as diferentes matérias da $2^{\mathrm{a}}$ série do $1^{\mathrm{o}}$ grau. As datas fazem parte dos registros da professora, iniciando pela primeira aula e chegando à última. Desse modo, consideramos que este caderno é uma fonte importante que auxilia na compreensão dos processos de ensino das disciplinas de Comunicação e Expressão, Matemática, Ciências e Saúde, Integração Social, Educação Artística, Educação Física e Ensino Religioso. Além disso, possibilita pensar sobre o que era considerado relevante para ser ensinado aos alunos de $2^{\mathrm{a}}$ série e, também, no conjunto dos conteúdos e das atividades escolares das disciplinas nessa época. O caderno traz, 
ainda, anotações referentes ao planejamento das aulas dessas disciplinas da $2^{\text {a }}$ série, referentes ao segundo semestre. Esse "Caderno de Planejamento" foi, provavelmente, precedido por outros do primeiro semestre de 1989.

No trabalho com os cadernos, é importante termos em conta que, por um lado, eles revelam indícios de práticas, demonstram escolhas e opções teóricas e metodológicas das professoras, mas, por outro, possuem limitações enquanto objeto-fonte de investigação, uma vez que eles não dizem nem mesmo retratam o cotidiano de sala de aula, das professoras e dos alunos. Apesar de estarmos atentos a isso, consideramos este caderno uma fonte "preciosa", pois ele indica aspectos do trabalho desenvolvido pela professora em sala de aula na escola de Vila Formosa.

\section{Caderno de Planejamento da Professora da Escola Padre Anchieta e o ensino da divisão}

O ensino da divisão era um dos conteúdos da disciplina de Matemática, ministrada durante o segundo semestre do ano de 1989 , na $2^{\text {a }}$ série do $1^{\mathbf{o}}$ grau, na Escola Padre Anchieta, o que se evidencia pelas anotações referentes a esse conteúdo com datas registradas no mês de agosto. Desse modo, acreditamos que, durante o primeiro semestre do ano de 1989, a professora nas aulas de Matemática tenha tido como foco o ensino das operações de adição, subtração e multiplicação, uma vez que há registros de aulas no caderno que trazem como conteúdo a multiplicação e a divisão juntas. Certamente, isso se explica pelo fato de a aprendizagem do processo de cálculo da divisão depender dos conhecimentos anteriores das operações de adição, subtração e multiplicação.

Os primeiros registros do caderno que tratam desse conteúdo referem-se às fases da divisão. Segundo as anotações, a professora propõe-se a trabalhar por meio da exposição e da explicação do conteúdo, bem como pela aplicação de exercícios orais e escritos. 
Figura 5 - Registro 1 - Introdução ao conteúdo de divisão

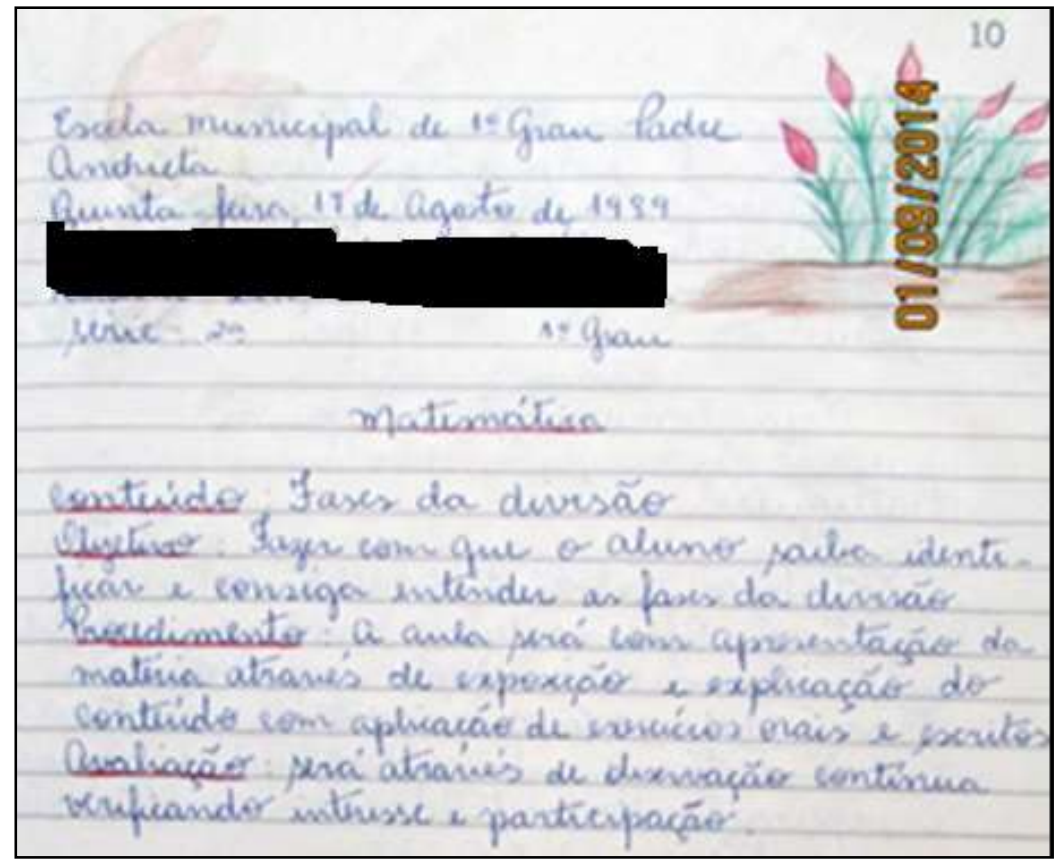

Fonte: Arquivo da Escola Municipal Padre Anchieta, município de Dourados.

$\mathrm{Na}$ tentativa de interpretar os registros do caderno, fica evidente no planejamento das aulas da professora a função da multiplicação no ensino da divisão, como podemos observar no objetivo da aula prescrito na Figura 6.

Figura 6 - Registro 2 - Divisão e multiplicação

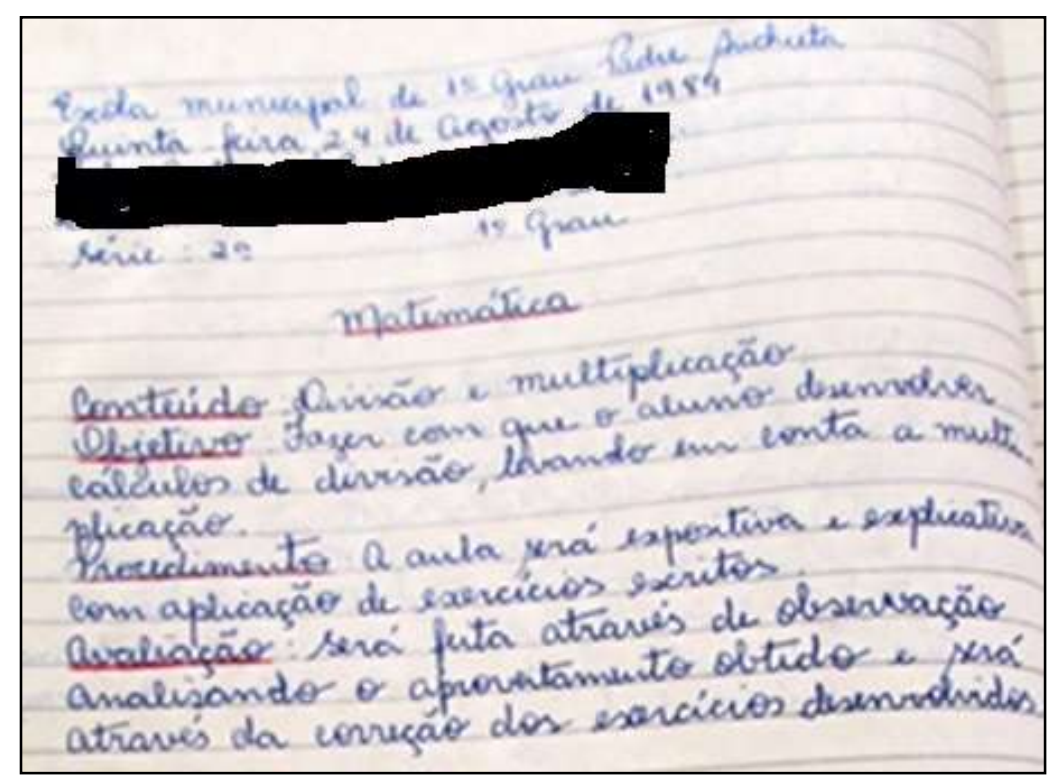

Fonte: Arquivo da Escola Municipal Padre Anchieta, município de Dourados. 
Nos registros do caderno, ainda é reforçada a associação do ensino da divisão ao da multiplicação, cujo conteúdo será desenvolvido por meio de exercícios. Percebemos que a prática de exercícios aplicando esses cálculos matemáticos era bem valorizada pela professora, tendo em vista um ensino eficaz e adequado, conforme revelam os objetivos da aula planejada pela professora.

Figura 7 - Registro 3 - Exercícios de multiplicação e divisão

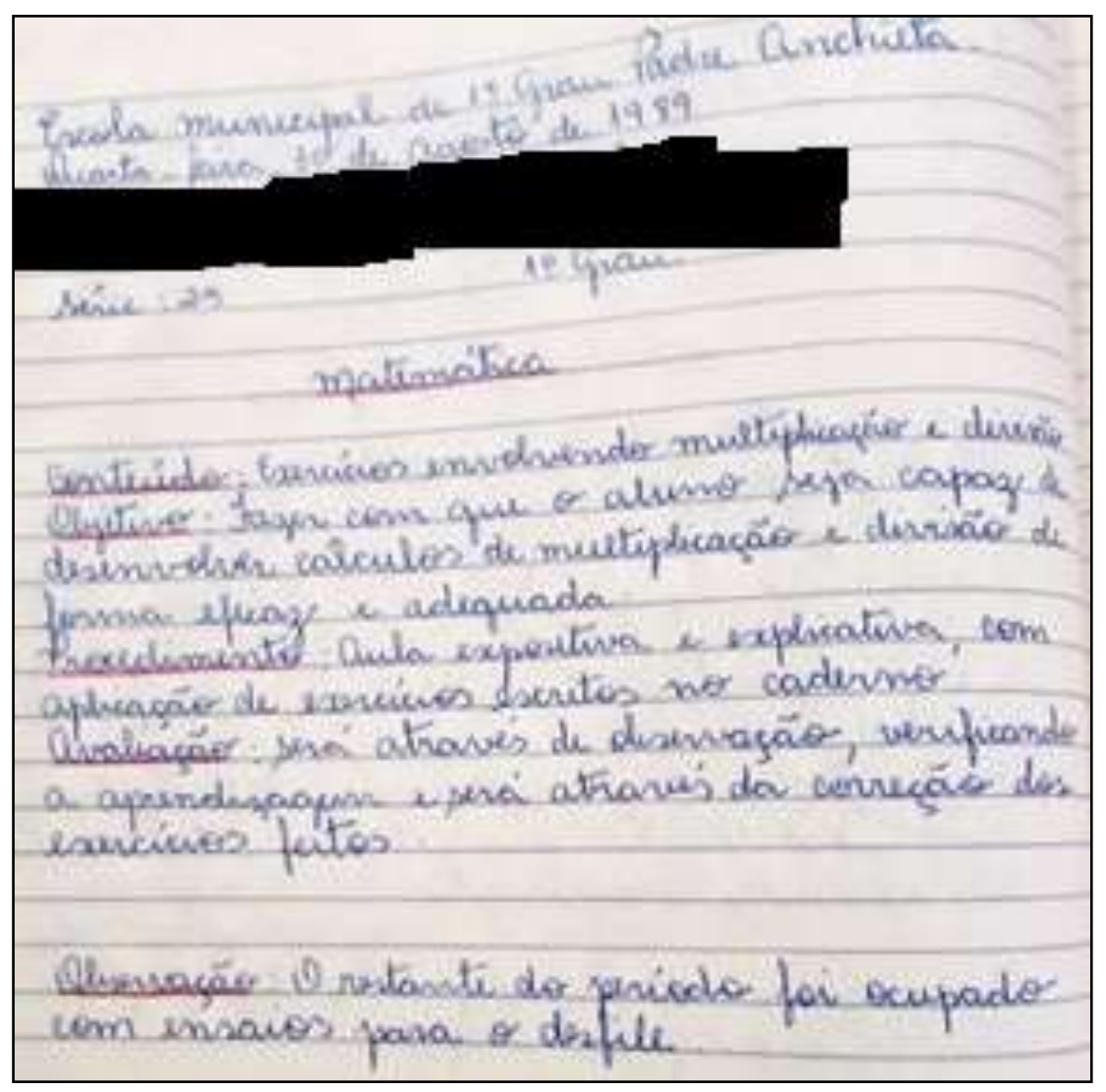

Fonte: Arquivo da Escola Municipal Padre Anchieta, município de Dourados.

O "Caderno de Planejamento" permite entrever também que a docente ao propor o ensino de divisão, tendo em vista a multiplicação, ainda se centra no ensino do algoritmo. Isso permite identificarmos que o ensino da divisão ficou pouco evidenciado frente ao ensino do cálculo da multiplicação.

Percebemos, ainda, nos registros do caderno da professora, indícios de concepções pedagógicas tradicionais quanto à necessidade da memorização, pois uma das aulas foi toda explicativa e voltada à aplicação de exercícios para que os alunos fixassem o conteúdo da divisão. Assim, percebemos que, no contexto em análise, é 
preciso ter em vista que o estudo das fases da divisão precisa ser repetido para ser aprendido pelos alunos.

Os estudos de Hébrard (2001) consideram os conteúdos dos cadernos como uma "prova irrefutável do trabalho realizado". Ao analisar os registros realizados pela docente, observamos que há indícios da prática pedagógica da docente evidenciados na metodologia em seus planejamentos no caderno e que estes estão estritamente ligados às tendências educacionais que regiam o ensino-aprendizagem nas décadas anteriores a 1980. Lembramos que em regiões de difícil acesso, como no caso do distrito de Vila Formosa, as renovações de tendências demoravam cerca de dez anos ou mais a serem exercidas pelos docentes em sala de aula. Observamos que os registros apresentados pela docente mostram indícios de um ensino tradicional e ao mesmo tempo influenciado por uma Matemática Moderna regida nas décadas de 1960 e 1970. Tais indícios são abordados por Pinto, Almeida e Dinis (2007), os quais mencionam que:

Os saberes priorizados nos cursos de Matemática Moderna, configuravam-se como um saber técnico, suscitando habilidades para o planejamento de testes, de atividades mais sofisticadas, que requeriam treinamentos para serem incorporados nas práticas modernas de ensino da matemática escolar (PINTO; ALMEIDA; DINIS, 2007, p. 1747).

Segundo o Ministério da Educação (BRASIL, 1997), esse movimento educacional incentivou o ensino de Matemática mais lógico, centrado no ensino das estruturas, dos algoritmos e da linguagem matemática, conforme apontam os registros do "Caderno de Planejamento" da professora representados nas Figuras 5, 6 e 7.

Ademais, observamos que o planejamento apresentado pela docente no "Caderno de Planejamento" está centrado no ensino dos algoritmos. Salientamos que os registros da docente, realizados na época, mostram-nos a influência de um ensino tradicional, assim como também da Matemática Moderna da década de 1960 e 1970. A educação brasileira era influenciada, segundo Lima e Maranhão (2014), pelo modelo Educacional Francês ERMEL (Équipe de Recherche de Mathématique a l'École Élémentaire de Paris), o qual apresenta estudos curriculares e didáticos para o ensino de Matemática. Esse sistema educacional partia do mais simples para o mais complexo em todos os conteúdos ensinados em Matemática. Assim, na divisão, ensinava-se 
primeiro a divisão com um número e contas exatas para depois ensinar divisões mais complexas.

Tendo em vista as anotações no "Caderno de Planejamento", notamos a falta de influência do National Council of Teachers of Mathematics - NCTM —, dos Estados Unidos, que, nessa época, já propunha um ensino centrado na resolução de problemas, na reflexão e na compreensão dos conteúdos matemáticos, o qual já se fazia presente em alguns Estados do Brasil.

Verificamos pela análise do caderno que as ações de planejamento da professora para ensinar a divisão estão centradas em uma concepção pedagógica tradicional e que há influência do movimento educacional da Matemática Moderna, apesar de o cenário escolar brasileiro, nos anos de 1980, em outros Estados do Brasil, já se mostrar diferente, baseado na influência do National Council of Teachers of Mathematics, dos Estados Unidos, o qual visa à reflexão sobre as situações problemas e suas resoluções (NCTM, 1980). Certamente, isso deve ser compreendido levando em consideração, como destacam os Parâmetros Curriculares Nacionais (BRASIL, 1997, p. 20), os “aspectos sociais, antropológicos e linguísticos”, das diferentes regiões e estados brasileiros, como é o caso do estado de Mato Grosso do Sul, que se encontra situado na região Centro-Oeste.

Desse modo, essa influência no ensino voltado para a Matemática Moderna, ainda nos anos de 1980, no interior do estado de Mato Grosso do Sul, deve-se à influência do movimento no ensino de Matemática, conforme assinala Wielewski (2008). A esse respeito, a autora esclarece que, no então estado de Mato Grosso, as formações ocorridas para professores acerca desse movimento educacional da Matemática Moderna somente foram iniciadas a partir de 1973 e prosseguidas até 1989. Isso possibilita entendermos que essa influência da Matemática Moderna perpassou e, também, permaneceu no ensino das escolas do estado de Mato Grosso do Sul, como revelado no planejamento da docente sobre o ensino de divisão na Escola Municipal Padre Anchieta de Vila Formosa, mesmo sendo submetida a outra estrutura educacional, que emergiu com a criação do novo Estado, a partir de 1977. 


\section{Considerações finais}

Ao longo deste artigo, que buscou analisar o ensino da divisão para crianças na $2^{\mathrm{a}}$ série do $1^{\mathrm{o}}$ grau, na Escola Municipal Padre Anchieta, situada na Vila Formosa, distrito pertencente ao município de Dourados, tomando como fonte principal de pesquisa um "Caderno de Planejamento" de uma professora que atuou em 1989, foi possível verificarmos os conteúdos presentes em uma parte da disciplina de Matemática ministrada em uma escola rural do interior de Mato Grosso do Sul. Em um cenário parecido com o mencionado na música "Menino da Porteira", no meio rural. Neste contexto, podemos afirmar que esse "Caderno de Planejamento" constitui-se em uma fonte importante para a compreensão das propostas do ensino da divisão nesse tempo e lugar.

De um modo geral, verificamos que esse caderno permitiu compreendermos e refletirmos sobre como ocorria o ensino da Matemática e, mais especificamente, o ensino da divisão, na $2^{\mathrm{a}}$ série do $1^{\mathrm{o}}$ grau, em uma escola situada no meio rural do interior de Mato Grosso do Sul. Assim, os cadernos escolares, enquanto fontes privilegiadas para a pesquisa, constituem-se como indícios do ocorrido em sala de aula.

Faz-se necessário pontuarmos ainda que esse "Caderno de Planejamento" da professora da escola rural de Vila Formosa contribui não só como registro da história dos processos de ensino da divisão dos números naturais, mas como uma possibilidade concreta para compreendermos e até mesmo problematizarmos o "vivido" na sala de aula nas séries iniciais do $1^{\circ}$ grau, em uma escola rural situada no interior de Mato Grosso do Sul. Além disso, oportuna verificarmos como a influência da Matemática Moderna se fazia presente ainda no final da década de 1980, um período em que já circulava, em outros países e até mesmo em outros Estados brasileiros, a tendência do ensino da Matemática voltado para a resolução de problemas, a reflexão e a compreensão dos conteúdos matemáticos, baseado no National Council of Teachers of Mathematics (NCTM), originário nos Estados Unidos.

Assim, o que ainda percebemos no ensino da divisão em uma escola rural do interior de Mato Grosso do Sul, em pleno final da década de 1980, é um ensino 
pautado na Matemática Moderna, partindo do conteúdo mais simples para o mais complexo em todos os conteúdos ensinados em Matemática, em que, no caso da operação da divisão, ensinava primeiramente as divisões com um número e resultados exatos, para depois ensinar divisões mais complexas.

\section{Referências}

ÁVILA, V. P. S. Educação Rural em Perspectiva Histórica. Revista Pensar em Educação, Ano 4, v. 4, n. 2, p. 1-21, mar./jul. 2018. Disponível em: $<$ http://pensaraeducacaoemrevista.com.br/2018/12/21/educacao-rural-em-perspectivahistorica-ano-4-v-4-n-2-jul-set-2018/>. Acesso em: 28 fev. 2019.

BICUDO, C. P. Educação Rural no Sul de Mato Grosso: um estudo sobre a história da Escola Padre Anchieta, do distrito de Vila Formosa, município de Dourados (1965-1974).2017. 30f. Trabalho de Graduação (Curso de Pedagogia) — Universidade Federal da Grande Dourados, Dourados, 2017.

BRASIL, Ministério da Educação. Parâmetros Curriculares Nacionais de Matemática. Brasília: MEC, 1997.

CARVALHO, M. M. C. Por uma História Cultural dos Saberes Pedagógicos. In: SOUSA, C. P. et al. Práticas Educativas, Culturas Escolares, Profissão Docente. São Paulo: Escrituras, 1998. p. 31-40.

CHARTIER, R. A História Cultural: entre práticas e representações. Lisboa: Difel; Rio de Janeiro: Bertrand Brasil, 1990.

FARIA, V. L. B. No caderno da criança o retrato da escola. 1988. 258f. Dissertação (Mestrado em Educação) — Universidade Federal de Minas Gerais, Belo Horizonte, 1988.

HÉBRARD, J. Por uma bibliografia material das escritas ordinárias: o espaço gráfico do caderno escolar (França - séculos XIX e XX). Trad. Laura Hansen. Revista Brasileira de História da Educação, Campinas, n. 1, p. 115-141, jan./jun. 2001.

GATTI JÚNIOR, D. História das Instituições educacionais: inovações paradigmáticas e temáticas. In: ARAÚJO, J. C.; GATTTI JÚNIOR, D. Novos Temas em História da Educação Brasileira: instituições escolares e educação na imprensa. Campinas: Autores Associados; Uberlândia: Edufu, 2002.

GUILLEN, I. C. M. O lugar da história: confronto e poder em Mato Grosso do Sul. Revista Cientifica, Campo Grande, v. 3, n. 2, p. 37-44, 1996.

GVIRTZ, S; LARRONDO, M. Os cadernos de classe como fonte primária de pesquisa: alcances e limites teóricos e metodológicos para sua abordagem. In: MIGNOT, A. C. V. (org.). Cadernos à vista: escola, memória e cultura escrita. Rio de Janeiro: Uerj, 2008, p. 35-48.

LIMA, G. L.; MARANHÃO, C. S. A. O caso da memorização das tabuadas de multiplicação. Ensino de Matemática em Debate, v. 1, n. 1, p. 1-25, 2014. 
MAGALHÃES, J. P. Tecendo nexos: a história das instituições educativas. Bragança Paulista: Editora da Universidade São Francisco, 2004.

MATO GROSSO. Mensagem apresentada à Assembleia Legislativa pelo governador de Matogrosso Fernando Corrêa da Costa. Cuiabá: Imprensa Oficial, APMT, CDR-UFGD, 1962.

MIGNOT, A. C. V. Um objeto quase invisível. In: MIGNOT, A. C. V. Cadernos a vista: Escola, Memória e Cultura escrita. Rio de Janeiro: EdUERJ, 2008.

MIGNOT, A. C. V. Cadernos escolares: um exercício de análise. In: HEES, M. P. N. et al. (org). SEMINÁRIO DE EDUCAÇÃO: MEMÓRIA(S), HISTÓRIA(S) E EDUCAÇÃO: FIOS E DESAFIOS NA FORMAÇÃO DE PROFESSORES, 2., 2004, São Gonçalo. Anais... São Gonçalo: UERJ, Faculdade de Formação de Professores, 2004. p. 83-90.

NAGLIS, S. G. B. "Marquei aquele lugar com o suor do meu rosto": os colonos da Colônia Agrícola Nacional de Dourados — CAND (1943-1960). 2007. 144f. Dissertação (Mestrado em História) — Universidade Federal da Grande Dourados, Dourados, 2007.

NATIONAL COUNCIL OF TEACHERS OF MATHEMATICS (NCTM). An agenda for action: Recomendations for school Mathematics of the 1980's. Reston: National Council of Teachers of Mathematics, 1980.

OLIVEIRA, B. C. A política de colonização do Estado Novo em Mato Grosso (1937-1945). 1999. 255f. Dissertação (Mestrado em História) - Universidade Estadual Paulista "Júlio de Mesquita Filho", Assis, 1999.

OLIVEIRA, I. B. de. Aprendendo com os cadernos escolares: sujeitos, subjetividades e práticas sociais cotidianas na escola. In: MIGNOT, A. C. V. Cadernos a vista: escola, memória e cultura escrita. Rio de Janeiro: edUERJ, 2008.

PINTO, B. N; ALMEIDA, A. F.; DINIS, M. A. Saberes docentes para o ensino da Matemática Moderna. VII Congresso Nacional e Educação - EDUCERE, 7., 2007, Curitiba. Anais... Curitiba: PUCPR, 2007.

PONCIANO, N. P. Religião, Cidade: o papel da Igreja Católica no processo de organização sócio-espacial de Fátima do Sul/MS (1943-1965). 2006. 231f. Tese (Doutorado em História) — Universidade Estadual Paulista "Júlio de Mesquita Filho", Assis, 2006.

SANTOS, A. A. C. Aprendendo a usar cadernos: um caminho necessário para a inserção na cultura escolar. In: MIGNOT, A. C. V. Cadernos a vista: Escola, Memória e Cultura escrita. Rio de Janeiro: EdUERJ, 2008a.

SANTOS, A. A. C. Cadernos e outros registros escolares da primeira etapa do ensino fundamental: um olhar da psicologia escolar crítica. 2008. 331f. Tese (Doutorado em Psicologia) Universidade de São Paulo, São Paulo, 2008b.

SANTOS, V. M. O nascimento dos cadernos escolares: um dispositivo de muitas faces. 2002. 134f. Dissertação (Mestrado em Educação e Cultura) - Universidade do Estado de Santa Catarina, Florianópolis, 2002.

SOUZA, R. F. Templos de civilização: a implantação da escola primária graduada no Estado de São Paulo (1890-1910). São Paulo: UNESP, 1998. 
VIÑAO FRAGO, A. Os Cadernos escolares como fonte histórica: aspectos metodológicos e historiográficos. In: MIGNOT, A. C. V. Cadernos a vista: Escola, Memória e Cultura escrita. Rio de Janeiro: EdUERJ, 2008.

VIDAL, D. G. Fim do mundo do fim: avaliação, preservação e descarte documental. In: FARIA FILHO, L. M. (Org.). Arquivos, fontes e novas tecnologias: questões para a história da educação. Campinas: Autores Associados; EDUSF, 2000. p. 31-43.

WARDE, M. Contribuições da História para a Educação. Em Aberto, Brasília, v. 9, n. 47, p. 3-11, jul./set. 1990.

WIELEWSKI, G. D. O Movimento da Matemática Moderna e a formação de grupos de professores de Matemática no Brasil. In: PROFMAT, 2008, Elvas-Portugal. Actas... Lisboa: Associação de Professores de Matemática, 2008. 